\title{
Healthcare Encounter Type
}

National Cancer Institute

\section{Source}

National Cancer Institute. Healthcare Encounter Type. NCI Thesaurus. Code C119231.

A classification or description of the visit by a patient or study participant to a medical professional. 